\title{
Probability analysis of seasonal rainfall pattern for Ananthapuramu district of Andhra Pradesh
}

\author{
B. LAXMAN, A. ANIL KUMAR, CH. RAMULU AND G. PRASANNA
}

Received : 25.07.2017; Revised : 28.08.2017; Accepted : 14.09.2017

See end of the Paper for authors' affiliation

Correspondence to :

\section{B. LAXMAN}

College of Agricultural Engineering (A.N.G.R.A.U.), MADAKASIRA (A.P.) INDIA
- ABSTRACT : Rainfall is the major controlling factor in planning of agricultural programmes, design and management of any water resource scheme. India is predominantly an agricultural country with about 60 per cent of the cultivated area under rainfed conditions. The present study was carried for Ananthapuram district which is one among the rainfed areas in the country.The design rainfall is calculated from the probability analysis. It is assigned some probability level of occurrence or exceedance. The daily or monthly rainfall analysis for a wide range of applications extending from real time monitoring and prediction of flood events to initialization and validation of numerical weather prediction (NWP), climate analysis and climate diagnostic study. The study showed there is a large variation in the rainfall received yearly as well as Kharif and Rabi seasons. Similarly the co-efficient of variation is 39.15 per cent for yearly rainfall, 57.35 per cent for Kharif and 65.18 per cent for Rabi seasons this indicates the annual rainfall data are less variable and is more stable or more uniform. The probability analyses were conducted for the year 2001-2012. Probability of getting 2012 year wise as well as season wise the yearly rainfall is $731 \mathrm{~mm}$ only five per cent and probability of getting $413 \mathrm{~mm}$ is 94.9 per cent. It indicates that the last 12 years trend shows the yearly rainfall will not cross $400-500 \mathrm{~mm}$ which is the bench mark for designing the crops that are to be grown in Ananthapuramu district. Similar trends were noticed in the probability analysis in season wise. When analyzed statistically there was a negative correlation between water requirement and yield and similarly positive correlation between rainfall and yield, the results are reflected. The trend values are shown linearly dependent. There is a perfect linear dependency on the trend values. The actual crop water requirements are progressively decreasing from 2012 to 2020.

- KEY WORDS : Rainfall, Probability analysis

- HOW TO CITE THIS PAPER : Laxman, B., Kumar, A. Anil, Ramulu, Ch. and Prasanna, G. (2017). Probability analysis of seasonal rainfall pattern for Ananthapuramu district of Andhra Pradesh. Internat. J. Agric. Engg., 10(2) : 550-555, DOI: 10.15740/HAS/IJAE/10.2/550-555. 